\title{
Walter Benjamin, a Methodological Contribution
}

\author{
Anca Pusca \\ University of London
}

\begin{abstract}
This article examines the work and philosophy of Walter Benjamin as an important source of information for international relations (IR) and International Political Sociology (IPS) scholars, particularly in light of his methodological contributions, which could provide important ground for movements such as the aesthetic turn in IR and everyday life/popular culture studies within IR and IPS. Benjamin's contributions are examined in light of his most controversial, albeit unfinished, project-The Arcades Project, a recently published volume that focuses on a selection of documents from the Benjamin archive; and a study by Howard Caygill on Benjamin's attempt to create a "new philosophy," and along with it, a new methodology for studying "experience." The article focuses on three main elements that stand at the basis of Benjamin's unique methodology: (1) his process of selecting the object of study; (2) his treatment of temporality and processes of change/history; and (3) his focus on the visual as key to escaping the limitations of traditional "philosophical" text.
\end{abstract}

Benjamin, Walter. (1999) The Arcades Project (H. Eiland \& K. Mclaughlin, Trans.). Cambridge: Belknap Press of Harvard University Press.

Marx, Ursula, Gudrun Schwartz, Michael Schwartz, and Erdmut Wizisla, EDs (2007) Walter Benjamin's Archive. London and New York: Verso.

Caygill, Howard. (1998) Walter Benjamin: The Colour of Experience. London and New York: Routledge.

Walter Benjamin is one of those rare contemporary scholars that truly evades disciplinary distinctions, establishing himself as a scholar of "experience" in its multitude of forms: material, architectural, emotional, visual, psychological, or aesthetical. He has been claimed by cultural theorists, sociologists, human geographers, linguists, philosophers, visual and political theorists alike, and it was only a matter of time before he would be claimed by international relations (IR) scholars as well. Benjamin has certainly been no stranger to our discipline. He has played an important role in the work of a number of critical theorists appropriated by IR: Benedict Anderson, Carl Schmitt, Jacques Derrida, Georgio Agamben as well as most of the "Frankfurt 
School" and its followers. His essays on history, violence, and art in the age of technological reproduction, often find their way into IR bibliographies, along with selections from the very rich selection of biographies and interpretations of Benjamin.

He has been officially inducted into IR's hall of critical theorists by Angharad Closs-Stephens in a recent chapter in Critical Theorists and International Relations (Closs-Stephens 2009), and his work is increasingly used by scholars associated with the more recent "aesthetic turn" in IR (Bleiker 2001), the study of "everyday life" in IR (Davies and Niemann 2008) and the wider intersection of the field of popular culture and IR (Barker 1999; Blum 2000; Roman 2003). Benjamin, however, remains a marginal scholar within IR, partially due to the fragmentary nature of much of his work, which lends itself more easily to marginal reflections on his most popular concepts of shock, aura, wish-image, thoughtimage, or flaneur. This in turn means that there has been little, if any, recognition of Benjamin's methodological potential outside of visual and urban studies.

This essay will seek to underline Benjamin's methodological potential for IR by focusing on three representative texts: Benjamin's most important, yet, unfinished project, The Arcades Project, which lays out his boldest attempt to create a methodological ground for a "new philosophy"; a recently published volume on the Benjamin Archive in Frankfurt that exposes Benjamin's interest in archiving and collecting as key to his proposed "new philosophy"; and Caygill's seminal text on Walter Benjamin: The Colour of Experience, which underlines visuality as key to Benjamin's new methodology. Each of these texts has been carefully chosen to underline the three specific methodological contributions that I see Benjamin making to IR and International Political Sociology (IPS): (1) a unique way of choosing our object of study; (2) studying change and transition through cultural transformations; and (3) transcending the limitations of text through the use of images and textual collages.

The Arcades Project, although an unfinished project, is perhaps the most developed example we have of how Benjamin sought to unveil his "new philosophy," and along with it, his "new methodology." Arguing that the object of study needs to be determined not by means of particular historical/philosophical traditions of inquiry that is classical philosophy-but rather by the very nature of the transformations that one is examining, Benjamin radically shifts the relationship between the object and the method of inquiry, by controversially arguing that: (1) the object and method are two sides of the same coin; (2) the object is most often an actual, physical object-buildings, roads, artifacts, and fashion-as opposed to a human subject; and (3) the relationship between the physical object and the human subject is mediated by images as opposed to text.

Benjamin's Archive examines in more detail Benjamin's unique way of choosing his object of study in his examination of the major transformations taking place in nineteenth-century Europe. Unlike the philosopher, Benjamin is not guided by abstract "concepts" and "ideas" but rather by physical objects. The choice of these objects follows the model of the collector who is equally guided by instinct, ability to recognize patterns and, unlike the historian, a sense of playfulness in how objects are arranged once collected. The collector of social artifacts for Benjamin is like an archeologist, who is less concerned with the question of filling in a historical timeline, and more fascinated by how the objects themselves capture change. Once the idea of change is disconnected from the idea of progress or evolution, it becomes simply a question of recognizing patterns of adaptation to the "new" and different levels of shock that the "new" brings about.

Caygill's Walter Benjamin: The Colour of Experience serves both as an explanatory/historical manual to Benjamin's work as well as, and perhaps more importantly, an attempt to conclude some of the implications of Benjamin's "new 
philosophy" and, I would argue "new methodology," for how social scientists go about doing their work. Abstracting from Benjamin's lesser known essays on color, Caygill is among the first social scientists to take Benjamin's critique of "text" and philosophy of "experience" to their logical extreme, and argue that Benjamin's ultimate aim was to "write" in "images" and do away with "text" as we now know it. Imagining a social science that does not rely on text as its main mechanism of inquiry, is, even today, a revolutionary idea. Caygill takes this idea seriously, tracking both Benjamin philosophical justification for how "color" is different from "form/line" and Benjamin's suggestions for how one may go about employing "color" and "images" as alternatives to text.

The choice of these three texts thus serves to strategically introduce the reader to Benjamin's idea of a "new philosophy" and showcase the specific implications of his "new philosophy" for larger methodological concerns in the social sciences, IR and IPS included: the object of study, the relationship between the physical object and the human subject, the physical object's analytical potential and alternatives to text as the main method of inquiry. The remainder of this article will analyze in more detail these three texts and their methodological implications, particularly in relation to the "aesthetic turn" in IR and the study of "everyday life" in IR and IPS.

\section{The Arcades Project}

The Arcades Project is Benjamin's last project, which, although unfinished, brings together in one place all of Benjamin's philosophical concerns and represents his boldest attempt to break with the state of philosophy at the end of the nineteenth century, both at the ideational as well as the stylistic (linguistic/textual) level. The project is certainly not a book in the conventional sense. It presents itself as an archive of working notes, citations, photographs and themes whose (dis)organization and classification is equally important to their actually meaning. Written under the influence of the surrealist movement in Paris, the book represents a broad textual and visual collage of the nineteenth century. Its ultimate goal, however, is difficult to determine, given the many incarnations of the project: initially conceived as a small essay on the Paris Arcades that followed Benjamin's previous essays on Berlin, Naples, and Marseille, and later developed into a larger expose-two different versions of which survive today, the project can be read as both a critique of philosophical historicism, along the lines of Benjamin's previous work, as well as a Marxist-inspired critical examination of capitalism and reification.

While Benjamin seems to have constantly added new dimensions to the project up until the moment of his death-he worked on it for more than 13 years- the main structure of the project remains more or less consistent in time, centering around a series of themes: Fourier and the Paris Arcades, Grandville and the World Exhibitions, Fashion, Louis Philippe and the transformation of the interior, Baudelaire and the concept of the flaneur, Haussmann and the Barricades, The Commune. It is these thematic concerns that constitute the core of the Benjamin's project, and while the larger framework in which they were arranged seems to vary quite radically-from the 1935 to the 1939 expose for example-one can easily suspect that these differences are a direct response to the editorial comments that Benjamin received from Adorno and his financial dependence on the Frankfurt Institute in New York. It is thus difficult to determine the extent to which differences in the two exposes are a result of external pressures and compromises as opposed to a natural evolution in Benjamin's thought. Although the exposes are supposed to provide the key to the so-called "Convolutes" - the list of citations that make up the largest part of the project: over 800 pages - the latter can easily be read as a work in itself. I would in fact 
argue that the Convolutes, more so than the exposes, are the key to Benjamin's most radical project.

"In Germany, the term Konvolut has a common philological application: it refers to a larger or smaller assemblage-literally, a bundle-of manuscripts or printed materials that belong together" (Benjamin 1982:xiv). The Convolutes can thus be understood as a form of textual collage, in which the pieces, although separate, come together to form one whole. It is unclear the extent to which the Convolutes, discovered years after Benjamin's death and reassembled several times by different scholars, maintain the original or intended ordering/categorization: Benjamin kept the citations which make up the Convolutes in a series of folders with different letter tabs, that separated the 36 different topics that make up the project. Despite the fact that the book seeks to more or less replicate the ordering of the original manuscript as initially printed in German, it is unclear whether this is indeed Benjamin's ordering, or whether the notes are complete. Coupled with the book's overwhelming size, the nontraditional format makes reading the book a daunting task: used to a particular fluidity of text, one is uncertain where to start, how to distinguish between Benjamin's own notes/thoughts and citations copied down from other texts, how to put different thoughts and ideas together, and more importantly, what kind of conclusions to draw. This, however, seems only to add to the volume's fascinating appeal.

The volume challenges all of our instincts as academics: that of schematically breaking down the text into concepts, logical flows and conclusions, of placing the text within a particular debate and discipline, of underlining or picking out citations, making it difficult, at least initially, to use. The impossibility of finding a single logic, scope, within the multitude of themes, citations and notes, leads to digressions and interpretations that although inspired by the text, often transgress it. As Weigel explains, the text does not allow us to construct and understand it as a consistent, fluid history/story. Because of its particular status, "the quotation attains a linguistic materiality and independence which make it readable in a variety of ways, but also resistant to the purpose of constructing history" (Weigel 1996:36). The quotations thus make up a volume that evades the possibility of a single, truthful interpretation: the textual collage appears differently to each reader, breaking the usual logical intentionality of text and transforming it into a more expressive, image form.

This falls neatly in line with Benjamin's earlier expressed attempt to form a "new philosophy," which does not search for truth, but rather stumbles upon it:

The object of knowledge, determined as it is by the intention inherent in the concept, is not truth. Truth is an intentionless state of being, made up of ideas. The proper approach to it is not therefore one of intention and knowledge, but rather a total immersion and absorption in it. Truth is the death of intention. (Benjamin [1963] 1998:36)

The concept, or idea, becomes merely an organizational device, a way of presenting and organizing unexpected contrasts: "Ideas are to objects as constellations are to stars" (Benjamin [1963] 1998:34). The Arcades Project thus emerges as a creative way of underlining and categorizing the material and ideational contrasts of the nineteenth century, in an attempt to provide a different kind of history: one that does not progress along a clearly set temporal line, one that does not follow logically from previously agreed upon key historical dates, and instead, one that emerges through an unlikely collage of objects, fashion, architecture and characters. If there is one conclusion to The Arcades Project, it is perhaps that the essence of the nineteenth century is in the image and the material object, not in text. 
Benjamin's intriguing technique of textual and visual collage that forms both the methodological as well as the larger philosophical basis of the volume is captured in The Arcades Project more so than in any of his other projects. Key to this collage is Benjamin's close attention to categorizing: the particular ordering of his notes, photographs and citations gives fluidity to the project, allowing for a logical flow between and across each of the different themes. The flow does not follow a linear format-neither temporally, nor spatially-but rather the format of a constellation of themes that provides an almost instinctual arrangement of ideas.

This breaking down of text and its logical flow that most often than not requires a particular progression, forms the basis of Benjamin's critique of philosophy and history, two of the foundational fields on which IR is based. Benjamin's potential methodological contribution to IR is thus directly connected to his critique of classical text and his attempt to transcend it through a number of different methodological techniques, including that of a textual and visual collage, the use of citations as a way of breaking down the authorship/readership barrier, and archiving and categorizing as key to preserving and uncovering the role of the "marginal" in research. This later technique is more specifically addressed in a volume recently published by some of Benjamin's archivists in Frankfurt, that will be examined in more detail below.

Some of these techniques have been attempted by different representatives of the "aesthetic turn in IR," particularly in the context of the role that poetic/literary text could play in academic text (Moore 2006), as well as the role of photographic images (Bleiker and Kay 2007) and film (Weber 2007) in academic argumentation. Without making direct reference to Benjamin, each of these attempts symbolizes a move toward establishing new norms for academic "writing" and IR methodologies/methods: Weber has managed to have her videos recognized as important contributions to the discipline and included them on her research assessment exercise submission, while Bleiker and Kay helped to introduce photographic images as important argumentation tools in themselves. Initially introduced as a "methodological" intervention in IR, the "aesthetic turn" needs to now more clearly define and target its methodological suggestions and fine tune its suggested methods. Benjamin's work could prove of great help in this endeavor.

\section{Walter Benjamin's Archive}

Walter Benjamin's Archive came out in 2007, and functions as a visual archive of Benjamin's work, including letters, notes, pieces of text, and photographs that are reproduced through photo stills to showcase Benjamin's own interest in collecting and archiving his work, as well as his intense focus on his workmethod, which included different writing styles, sorting, and organizing techniques, as well as a fascination for the material, texture, and surface on/through which his work was laid out: particular types of paper, notebooks, or pens. The book seeks to show the extent to which his work and his work-method are intertwined and also uncover a series of texts and notes, such as Benjamin's own riddle collection and his lists of his son's first words, that place him under a different light: Benjamin in his free time, creating riddles and being a father. His playfulness with these texts and lists as well as his fascination for his own child's play with words, provide important insights into his attempts to move beyond the written text and establish a new kind of surface on which his "new philosophy" could best be presented. 
Benjamin was an avid archivist and collector:

\begin{abstract}
Benjamin's mode of working is marked by the techniques of archiving, collecting, and constructing. Excerpts, transpositions, cuttings-out, montaging, sticking, cataloguing, and sorting appear to him to be true activities of an author. His inspiration is inflamed by the richness of materials.... Benjamin believes that... peculiar to the collector is a relationship to objects which does not emphasize their functional, utilitarian value-that is their usefulness-but studies and loves them as the scene, the stage of their fate. (Marx, Schwartz, Schwartz, and Wizisla 2007:4)
\end{abstract}

The process of writing and creating for Benjamin is thus much more similar to that of an artist or a painter. It is not his mind alone that is involved, but also his hands, his physical interaction with the text, the paper on which it is laid out, the pen and ink with which it is written or recopied. By showing photographic reproductions of letters, notes, notebooks, and photographs that are now part of the Benjamin archive in Frankfurt, the volume allows for a different kind of interaction with his text: one sees not only the changes and playfulness in his handwriting-his experiments with smaller and larger print, diagonal as opposed to horizontal writing, poem layout of what should be prose-but also the rigor of his method: the erased text, the comments on the margins, the rejection of previous ideas, the lists and graphs that seek to re-create a logical rigor in a visual fashion.

The documents reproduced in the volume, particularly Benjamin's notes to himself, lists and fragments of manuscripts, reveal that Benjamin's work-process did not rely on collecting citations alone, but rather of on a complex system of categorizing. This strongly suggests once again that The Arcades Project was indeed not just a list of notes, a background research on which the final text would be based, but rather the project as it was meant to be. Organized around 13 different sections-Benjamin as Archivist, Collecting and Dispersal, Micrographies, Russian Toys, His Son's Words and Turns of Phrases, Notebooks, Picture Postcards, Composing, Building, Weaving, Graphic Forms, The Arcades Project, Arcades and Interiors, Riddles, Brainteasers, Word Games, Mosaics in Siena - the volume emphasizes not only Benjamin's near obsession with the preservation and categorization of his own work but also the way in which he found inspiration in the objects and people immediately surrounding him.

The notes on riddles, brainteasers, and word games as well as his notes on his son's words and turns of phrases are unique and rarely explored in the Benjamin literature. They present Benjamin as a caring father, who, although spent little time with his son, was fascinated by the way in which he learned and applied words in the most unusual contexts. These notes clearly suggest Benjamin's continued interest in finding new ways of escaping the strict rules of text and language: while his collecting, writing, and collaging practices provided one clue, his son's approach to language provided another, one that Benjamin had played around with throughout his life through his writings on his own childhood-The Berlin Chronicle-and his general fascination with the way in which children approach the world.

For his own child, language becomes a way to paint the world: its use is more flexible, and follows rules of association-between colors, actions, and words-as opposed to strict grammatical rules. Instead of imitating, the child is creative: the associations between particular words and objects are not always fixed, and language does not take precedence over perception but rather the opposite. The struggle to express what he sees and feels, point to the strict limitations of language and its text form, proving to Benjamin once again, that his own distancing from text was perhaps the right move. 
Given Benjamin's longtime concern with questions of mechanical reproduction, such as photographic practices, the aesthetics of the volume itself and the technologies that allowed its production become particularly telling: by photographing Benjamin's notes, the text literally becomes an image, a visual as opposed to a linguistic experience. This is even more striking for those who are not German speakers, and thus cannot relate directly to Benjamin's reproduced text but rather need to refer to the translation on the opposite page. In this context, the reproduction of Benjamin's text becomes nothing but an image, while the translation continues to function as the more traditional text. One reads the translation line by line, while one generally glances at the reproduction page as one would at a photograph or a painting.

Perhaps more so than any other Benjamin volume, Benjamin's Archive manages to give the reader a much better sense of Benjamin's writing process as directly connected to two of his other passions: collecting and visual art. His text and careful language choices are revealed as elaborate attempts to transcend the limitations of language in both its structural and written form, and to allow the image to take center stage. Looking for creative ways to transform text into image, Benjamin experimented with a series of potential methodologies that serve both to break the flow and progression of classical text as well as to allow the meaning of the word to escape strict grammatical rules, thus providing more flexibility to language: different script types, types of pagination, and visual ordering are used to create particular constellations of thought.

While Benjamin's passion for collecting and visual art is sometimes difficult to imagine in the context of IR, Christine Sylvester's recent contribution Art/Museums: International Relations Where We Least Expect It, opens up a new realm of possibilities: examining the implications of art looting in the context of the Iraq war, the architectural debates surrounding the destruction and rebuilding of the twin towers in New York, as well as the Guggenheim, Getty and British Museum collections, she argues that the realm of the "international" needs to be expanded to include, for one, art museums as deeply political institutions. Given that an art museum's main purpose is to collect, preserve and exhibit, the parallels to Benjamin's thought are unmistakable. Although Sylvester mainly references Benjamin's essay on The Work of Art in the Age of Mechanical Reproduction and not his other reflections on art and collecting, she does employ Benjaminian inspired ideas of art as "philosophiz[ing] by visual means" (Sylvester 2009:9) — through the work of Arthur Danto, and ideas of our everyday environment as "a giant museum" (Sylvester 2009:11)—through the work of Jean Baudrillard. She also describes the relationship between art, museums and IR, as a collage, a technique much discussed and admired by Benjamin.

Art and experience, as well as art and philosophizing by visual means are thus important connections that Sylvester argues could and should play a more important role in IR. Bringing Benjamin into this discussion might help bridge the sometimes dangerous gap of relying too much on his middle men-including people such as Danto and Baudrillard-and not enough on their original inspiration, while also focusing the discussion on the methodological implications of such interventions in IR. Caygill's volume on The Colour of Experience serves as one model on how such an intervention might be attempted.

\section{Walter Benjamin: The Colour of Experience}

Walter Benjamin: The Colour of Experience is one of the best attempts to reconstitute and trace Benjamin's thought throughout his career and among pieces of work that often appear more disconnected than they really are. Caygill identifies Benjamin's lifelong concern as that of establishing a "new philosophy" focusing on the concept of experience in direct contradiction to Kant's dominant philosophy 
at the time. Diligently digging through Benjamin's more established essays as well as some of Benjamin's more obscure ones, Caygill draws a clear connection between two aspects of Benjamin's work that many have chosen to treat as separate: his more esoteric philosophical work that he produced early on in his academic career and his much lighter notes and essays, that emerged after Benjamin was denied any official academic role, on different aspects of the material and cultural history of the nineteenth century.

Caygill follows three "interpretative strategies" throughout his book: (1) the Kantian origin of Benjamin's concept of experience; (2) the transformation of philosophy into cultural history; and (3) how the model of experience emerges from the visual rather than the linguistic field (Caygill 1998:xi). Each of these interpretative strategies marks an important step in Benjamin's work: the first strategy marks his initial training and interest in classical philosophy and his first attempts to critique Kant through his concept of allegory, the second marks his growing concern in questions of culture and materiality, while the third and last marks the final stage of his research and increasing interest in aesthetics, visual studies and technology. Each of these builds upon each other and feeds off earlier conclusions, making Benjamin's work much less fragmentary than initially perceived.

Arguing that at the center of each of these strategies lies the concept of experience, Caygill explains Benjamin's starting point as a basic disagreement with Kant's two main assumptions: that there is a distinction between the subject and the object of experience, and that there can be no experience of the "absolute" (Caygill 1998:1). Going back to Benjamin's early writings on perception, fantasy, and color, Caygill argues that this disagreement is directly related to Benjamin's unique understanding of (historical) space and time as well as his unique understanding of origin, as addressed earlier:

\footnotetext{
...it is crucial for Benjamin's argument that space and time (Kant's forms of intuition) be regarded as modes of configuration whose plasticity, or openness to other forms of patterning, can "decay" or be otherwise "transformed." Space and time which feature as the givens of transcendental philosophy become modes of configuration which can be understood speculatively as providing the contours of but one among many possible configurations of experience. (Caygill 1998:5)
}

Space and time are thus not constant throughout history. In fact, they are the best "reflectors" of historical change: with every great moment of change, our relationship to both our lived space as well as our perception of time changes. Benjamin's genius lies in his attempt to track precisely how this relationship changed throughout the nineteenth century by focusing on the lived space itself, the relationship to time in light of new technologies and new experiences, and the physical and psychological transformation of the subject: the stress of modern times as expressed through experiences of shock, the dreams of modern times as expressed in fashion and architecture. All of this, he found concentrated within the Parisian arcades: a microcosm that imitated and captured, perhaps better than anything else, the major transformations of the nineteenth century.

Benjamin's transition from philosophy to cultural history is increasingly felt in his essays following the rejection of his habilitation and partially inspired by his nomadic lifestyle while in exile in Paris and his travels to Italy and Russia. His fascination with the Paris Arcades, triggered most likely by the reading of Aragon's volume Le Paysan de Paris, marks Benjamin's increasing conviction that cultural history is one of the best ways to access and examine the concept of "experience" and historical changes in our perception apparatus. Adopting a language significantly different from his previous, philosophical writings, 
Benjamin shifts gears only to the extent that he has found a different medium/methodology of examination. Cultural history and its relationship to the arts and aesthetic theory provide him with a series of new tools through which to reassess the relationship between experience and "truth."

The majority of these tools rely on the prioritizing of the visual/image over text. Caygill tracks Benjamin's development of these tools back to his earlier essays on color, which, according to Benjamin, provides in its essence an important alternative to text and the graphic line on which written text relies. Unlike text, color communicates itself rather than any kind of essence, its objectivity being related not to form but rather to a certain idea of "pure seeing" which creates no object/subject separation-children for example, experience this kind of pure seeing (Caygill 1998:84-85). Color is for Benjamin not just paint on a canvas, but rather a material/physical element that shapes all of our external perception: from buildings, to printed images-such of photography and film-to nature. Just like words, colors and images help to organize experience, yet they do so intuitively as opposed to rationally. This is not to say that color/images cannot be manipulated in a rational manner.

Benjamin's transition into cultural history and aesthetic theory should, however, not be viewed as a jump into another discipline. As Caygill well argues, his point of departure and main concern: the relationship between experience and truth, remains the same. Benjamin is as much of a philosopher as he was when writing about Kant. His methodology however has turned toward what he would label as the marginal:

\footnotetext{
The eye for this marginal domain is for Benjamin characteristic of the "new type of researcher" who seeks the meaning of a work not by inserting it within historical or formal narratives, but by examining the disarticulartions of form and content and thus uncovering the "composition" or tracing the translation of what is exterior to the work into the medium of art. (Caygill 1998:91)
}

For Benjamin, most modern human creations fall into the medium of art: from architecture and city planning, to industry, technology, visual, and material reproduction. The job of philosopher is thus similar to that of an art critic: untangling the relationship between the work of art, its medium and what lies exterior to it. Most importantly then, the philosopher's job is not to untangle historical text, but rather to immerse himself/herself into daily life, into the rhythm of the city as the modern center of human activity, and into the nature and usage of modern objects/production. The philosopher gazes/looks outward to things as opposed to text/books alone. Unlike text, things are capable to return our gaze: "Things perceive us; their gaze propels us into the future, since we do not respond to them but instead step among them" (Benjamin cited in Caygill 1998:8).

Caygill argues that the examination of the work of art as human creation-Benjamin focuses mainly on architecture and fashion as two examples-develops in Benjamin along three separate dimensions:

\footnotetext{
The first regarded the work as a site for experimentation and the invention of new modes of experience while the second saw it as an occasion for tactile critical enjoyment by analogy with architecture; to these is now added the view that the work of art is a form of cathartic inoculation against the psychotic development of the energies generated by technology. (Caygill 1998:114)
}

These three dimensions capture the potential of Benjamin's unique methodology, setting out three clear research goals that could prove essential for the direction of the social sciences today: (1) experimenting with/inquiring into the development of new modes of experience; (2) analyzing the relationship 
between these new modes of experience and enjoyment; and (3) understanding the extent to which modern art (broadly speaking) serves to reflect on and protect against modern shock.

Benjamin's methodology employs a number of very specific techniques, many of which could prove useful to the way in which social scientists and IR scholars choose their case-studies and "objects of study," study processes of change and transition, and understand and exploit the visual "turn" in modernity. The remainder of the essay focuses on how Benjamin's develops and exploits these techniques, offering a number of suggestions as to how some of these could be applied within IR.

\section{Choosing the Object of Study}

Benjamin is a representative of the phenomenological tradition, and as such, he places much of his emphasis on "things" and "material objects" as opposed to "human subjects." Experience for him, is a particular kind of interaction with the "material" around us, and is not limited to the human subject alone. Objects and materials experience history alongside living beings, and carry within themselves stories that are otherwise erased and distorted in the human mind. Objects have a revelatory function: at the right time, under the right circumstances, the stories captured within these objects are revealed. Three of Benjamin's main concerns are thus: to explain the circumstances under which such stories become visible, the "objects" that are more likely to reveal them and whether/how this visual experience should/can be translated into text. According to this, perhaps oversimplified account, Benjamin appears to be no different from an archeologist. While his inspiration did partially come from his fascination with archeology, Benjamin does, however, remain very much interested in the human subject, despite his overwhelming focus on objects. How, thus, are objects connected to the human subject?

Benjamin describes the relationship between the two as a form of doublewatching/mutual observance: the human observes the object and vice versa. The object becomes not only the material embodiment of human imagination and creation, but also of human destruction and hesitation. The object is thus the ultimate human "text": history and the story of human "progression" is written into the very creation, use and destruction of such objects. In his first major book-length manuscript, his habilitation, Benjamin chooses to examine objects that are placed within an "allegorical" context: the theater, and more importantly, a particular form of historical theater: German tragic drama (Benjamin [1963] 1998). The "objects" on the theater stage are all evocative fragments of "time": signaling in this case the transition from the sixteenth to the seventeenth century.

Benjamin goes on to argue that the fragmentary nature of theater: through its different props, scenes, sets, and characters, as well as through its ability to manipulate space/the scene to transgress time, creates an interesting model for understanding real-life architectures. In fact, his later, unfinished project on the Parisian Arcades follows to a large extent his previously examined model of the German tragic theater: the scene in this case is the city, and more specifically, the shopping arcades, and the characters are no longer actors but rather the city's inhabitants. Just like the theater stage and its props becomes a historical text in itself for unveiling the transformations that took place at the end of the sixteenth century, the Parisian arcades and their props, become, for Benjamin, a historical text that unveils the transformations taking place at the end of the nineteenth century.

In many ways, thus, theater props and shopping arcades become for Benjamin material "essences" that capture, more so than other objects, a particular 
historical experience, a sense of "truth," that can only be expressed "visually" as opposed to "textually." These "essences" are, however, much unlike Husserl's essences: they do not simply exist within "things" themselves but are instead determined by direct changes in human perception apparatus. As humans are increasingly silenced by war, violence and shock, language is replaced by visuality and text by images. Objects become unlikely translators and bearers of historical memory. To arrive at these material "essences," Benjamin does not follow the classical phenomenological method of "bracketing", as described and implemented by Husserl and his followers, but rather develops his own mechanism of selection: in his case the "bracketing" is not an arbitrary choice to focus on a particular phenomenon/object, but rather intuitively imposed by the nature of historical/material transformation itself: the object reveals itself as essence(tial) through its ability to capture all of the classical historical planes: the past, the present and the future. An "essential" object is thus one which breaks the human silence on a particular subject and expresses, through its very form, the "stream of becoming and disappearance."

Moving the object of study from the human subject to the material object can have a radical effect on how we approach IR. As a filter of both human intentionality across time as well as nature/history's reactions to those intentions, the material object in its physical transformation/preservation becomes one of the most faithful witnesses to change. Embedded in the object are all the different phases of change: from the initial dream to first-time glory and decay. As the ultimate proof of change, the object is the sign of "progress," "stability" and "recession," an efficient barometer of expectations, ideology, "foreign" presence, "development" or "underdevelopment," and future potentiality. The object is the ultimate ambassador-from Norwegian architecture, to Italian luxury fashion and accessories, to French wines or Chinese-made infrastructure-as well as the ultimate negotiator. The object carries within it both its economic, social and political context as well as the human touch/mind who created it as well as the human gaze that interprets it. More so than anything else, the object tracks important changes in the human perception apparatus, clearly marking changes in priorities as well as processes of adjustment to change.

Roland Bleiker, Cynthia Weber, and Christine Sylvester's work are only some examples of how the material/art object—or in some cases the image-can become a central object of study in IR. However, while new interventions within the "aesthetic turn" are expanding our methodological and ontological horizons, too many of these interventions remain anchored in "classical" sites in IR-war, zones of conflict, terror-and perhaps too few dare to reach out into the realm of the "everyday." Perhaps this is where disciplinary divisions and realignments are most visible: as IR scholars reach out into the fields of art theory and aesthetics, they are careful to maintain a respectful distance from cultural and visual theorists and philosophers, by holding on to contexts that, for the most part, remain unquestionably "political." This is where Benjamin might once again come to the rescue, ${ }^{2}$ by offering a much wider variety of possibilities: from fashion to architecture, to publicity and technology. For him, the object of study is dictated less so by disciplinary boundaries, and much more so by the context of one's research.

\footnotetext{
${ }^{1}$ Gearing compares Husserl's methodology of bracketing to the process of bracketing in mathematics: "Bracketing, as in a mathematical equation, suspends certain components by placing them outside the brackets, which then facilitates a focusing in on the phenomenon within the brackets" (Gearing 2004:1,430). For Husserl thus the method of bracketing was one by which one was able to suspend all previous knowledge and preconceptions to focus in on the "essences," separating in a way consciousness from the world and helping to create a "reflective stance" (LeVasseur 2003:411-413).

${ }^{2}$ At the risk of sounding both repetitive and perhaps, in some eyes, too optimistic in terms of what Benjamin has to offer...
} 


\section{Understanding Change and Transition}

Benjamin is above all fascinated by processes of change, which he seeks to understand differently from the traditional historicism of his time: for him, history does not progress along a clearly marked temporal line, but rather unfolds rhythmically in a constant ebb and flow that links the past, present and future. To analyze change, Benjamin does not rely on the identification of "key moments" or the bracketing of particular time periods, but rather on the "process of becoming and disappearance" as marked in his carefully chosen objects of study. Just like tragic drama becomes emblematic of changes occurring at the end of the sixteenth century in Germany, the Parisian arcades become emblematic of nineteenth-century France. The process of becoming and disappearance is marked not temporally but physically and spatially: it is the object that comes into being and physically disappears, leaving behind ruins, memories and "wish-worlds" for the future. Benjamin's notion of change and history cannot be disconnected from his understanding of the concept of origin, which is:

\footnotetext{
...not intended to describe the process by which the existent came into being, but rather to describe that which emerges in the process of becoming and disappearance. Origin is an eddy in the stream of becoming, and in its rhythmic movement it swallows the material involved in the process of genesis. (Benjamin cited in Caygill 1998:57-58)
}

If one accepts this particular understanding of origin and history, then the study of change no longer relies on carefully identified key temporal moments (revolutions, coups, and wars), but rather on the way in which these moments have been physically marked into our surrounding environment: change has to be visible to be internalized, just like it has to be understood and interpreted to be acted upon. A mere declaration of change, such as "we are now independent!" or "our country is at war" or "the economy is experiencing its sharpest downfall since 1929" is not enough to mark as moment as significant in history. In fact, Benjamin seems to suggest that not only can we not identify change until it is exhibited physically, materially, and spatially, but also that we cannot understand it, until the process leads to the physical/material/spatial and perhaps also visual destruction of what lied there before. The material melange of the city, and the arcades in particular, provides Benjamin with a visual expression of history's ebb and flow: the recent ruin marks not only the moment of disappearance but also that of becoming. Stripped bare, a building unveils the very process of its construction, its battered existence and faded glory at the moment of decline. Stripped bare, a building also unveils the dreams that supported it before its structure even existed, the "wish-worlds" it has helped create and the models it provided for the future.

As Katherine Arens nicely explains, Benjamin seeks to identify precisely those "centers around which all other period understandings of that city are organized, within that era's economic rationales." (Arens 2007:48) Change is concentrated in the image and materiality of the city, to the extent that key centers of the city, such as arcades, are able to preserve within their own physical transformation both the economic as well as the social and political rationales of a particular time. Uncovering these rationales through an examination of the material body of the city becomes Benjamin's challenge and method. In a different article, I have sought to explain this unique method in light of a so-called process of "aesthetics of change," whereby change is directly assessed in light of its physical, material and visual expressions (Pusca 2008).

This intricate relationship between change and materiality/visuality creates a number of different opportunities for both positive and negative manipulation 
of change (and its interpretation), but more importantly, an opportunity for understanding the extent to which the present as well as the future rely on our ability to visually/physically recognize them as such. This detaches ideas of the past, present and future from clearly determined temporal moments and instead, attaches them to individual (and collective) processes of perception and recognizability: the past is the past to the extent that we recognize it a such and the same goes for the present and the future: "every present day is determined by the images that are synchronic with it: each 'now' is the now of a particular recognizability." (Benjamin quoted in Arens 2007:51) This implies that change is ultimately a moment of change in perception that is triggered both by a material/visual reflection of change as well as by an individual and collective "perceptual" adjustment to that change: what we until recently recognized as the present, we now recognize as the past, and what we until recently thought of as the future, we now think of as the present.

Like history, IR attaches change to key events occurring in specific spaces at particular moments in time. If one is to follow Benjamin's model, then perhaps we would no longer be talking about the Cold War and post-Cold War as before and after 1989, but rather in light of individual local and material transformations that clearly mark a visible change: the physical destruction of the Berlin wall, the first shopping malls of Eastern Europe, the removal of Stalin's portraits from former Soviet schools, the issuing of new passports. With change both visible and palpable, one cannot only pretend to be able to capture it through text/language. The literature on "transitions" and "democratization" in the context of IR offers some very interesting possibilities for taking such examinations from the realm of the "textual" into the realm of the "visual." Some of these possibilities have in fact already been explored by a number of different scholars, including Susan Buck-Morss (2000) and Svetlana Boym's (2001) work on the post-Communist transition in the former USSR-through visual examinations of transformations in the everyday landscape of the transition, as well as some of my own work on post-Communist Romania-through visual examinations of the Romanian New Wave (Pusca 2009a) and the industrial wasteland (Pusca 2009b). The concept of "change" might thus offer an interesting anchor for future inquiries within the "aesthetic turn" in IR.

\section{From Text to Images}

Perception and visuality play a key role in Benjamin's work and influence his unique methodology in at least two different ways: (1) the object of study is a material/visual object as opposed to text and (2) Benjamin's reflection on this material/visual object of study seeks to take a form that is significantly different from traditional "philosophical text." For Benjamin images/visuality become text. Understanding images in light of the initial Greek meaning of the word: likeness, similitude, resemblance, as opposed to its contemporary meaning of representation (Weigel 1996:20), Benjamin develops an intricate system of classification and interpretation of images that relies on a number of important concepts including that of "thought-image," "wish-image," and "dialectical image."

Thought-images are the process by which the "now" is translated and becomes interpretable/readable "text." Differentiating between images and text, Benjamin suggests that thought-images are more primal than language: they undergo a different mental translation process by which images are automatically transformed into an "idea" or a "thought" that need not necessarily have a linguistic/textual expression. Thought-images are thus not the verbalized thoughts triggered by a particular site, but rather individual "world images" that form an individual's instinctive opinion of the present or what he/she sees. 
Thought-images lie at the basis of Benjamin's attempt to transcribe and discuss these images in a formal, written form that escapes the normal conventions of "philosophizing." Suggesting that thought-images follow a similarly fractured and collage-like format to that of the actual process of seeing itself, Benjamin seeks to transcribe them into his own version of textual collage that makes use of citations, different writing styles, photographs, and calligraphy to express breaks, changes in vantage points, and temporal jumps.

Unlike thought-images, wish-images are both a mental as well as a visual/ physical expression of individual and collective desires (or manipulation of those desires). According to Benjamin, wish-images:

\footnotetext{
....are images in the collective consciousness in which the old and the new interpenetrate...in them the collective seeks both to overcome and to transfigure the immaturity of the social product and the inadequencies in the social organization of production... what emerges in these wish-images is the resolute effort to distance oneself from all that is antiquated-which includes however the recent past. (Benjamin 1982:4)
}

Fashion and architecture are for Benjamin two important domains in which wish-images become particularly visible (Weigel 1996:x). Fashion, which Benjamin describes as the tiger's leap into the past, is also the tiger's leap into the future. Both fashion and architecture become mechanisms of creative material entrapment: through them and their imitation of our bodies, we explore our inner physical and mental desires and in turn, express them outwardly/materially through new fashion/architecture (Weigel 1996:19). Weigel thus argues that the city, fashion, interiors, objects, and architectures are for Benjamin the dreamwriting of the collective (Weigel 1996:35).

While all images are dialectical according to Benjamin, who argues that: "image is dialectics at a standstill. For while the relation of the present to the past is a purely temporal, continuous one, the relation of what-has-been to the now is dialectical: is not progression but image, suddenly emergent" (Benjamin cited in Schwartz 2000), they only arrive at readability at a particular point in time (Weigel 1996:109). Judging from his own choice of dialectical images to examine, it seems that this particular moment is more often than not the moment of ruin, destruction and disappearance (or push into the marginal domain). The "reader" of dialectal images is not just any person: he/she is generally a marginal figure himself/herself: the child, the flaneur, the homeless, and the whore. Marginalized by society, and text, these characters appear as unlikely readers/translaters of "nowtime." The choice for the marginal character seems to be imposed by Benjamin's desire to write "text" differently: not only through unusual "images" but also through unusual "eyes." For him, traditional text reflects not only the limitations of language but also of the person writing. Writing in images seeks to forgo the need to translate into language the untranslatable as well as the tendency to privilege a particular writer/seer.

While writing in images might still be a long way from becoming commonplace in any of the social sciences, IR included, the transition seems to be on its way: the "aesthetic turn" in IR is only one marker of that transition. As new technological innovations on the Internet such as Facebook and YouTube are making waves not only in the world of 13- to 21-year-olds but also in important presidential campaigns, as major newspapers are shifting to online versions and increasingly rely on photography, slideshows, and documentaries to tell their stories, as wars are becoming increasingly virtualized, the image will inevitably become an essential object of study in all of the social sciences, with methodological questions lying at the core of these analyses. IR has a choice of whether to be at the forefront of these studies. 


\section{Conclusion}

This essay has sought to introduce Benjamin not only as an interesting cultural philosopher, but more importantly as a scholar very much interested in the methodological foundations of the social sciences and philosophy in particular. As such, Benjamin could have important insights into the way in which we approach the study of IR today, offering a potential new ground for movements such as the "aesthetic turn" in IR, everyday life in IR and popular culture in IR. As new technological innovations are pushing us to examine the increasing role that images play in our everyday life, social sciences, and IR in particular, need to take up this challenge by radically changing the way in which it conceives of the relationship between academic scholarship and "text," as well as pushing forward new methodologies that can creatively engage with the relationship between the image, object, and subject. This article has suggested that Benjamin's reflections on art, the image, textual and visual collage, the collector and the object can provide important launching points into examinations on the role of photography, film, and visual perception in today's everyday environment. While the "aesthetic turn" in IR has already attempted such examinations, the essay suggests that these need to branch out into contexts other than wars, zones of conflict and terror, such as "transition" and "democratization" studies or studies on the notion of "change."

Benjamin's methodology as embodied in his "new philosophy" has significant implications for one of the most important practices of scholars today: writing. While IR text today continues to follow to a large extent the established rules of classical philosophical text, the questionings of these rules and their role toward achieving knowledge is essential. Benjamin's critique of classical text offers at least three potential "methods" that could be employed to release its full potential: (1) breaking up the actual format of the text through textual collage practices and citations; (2) breaking up the logical progression of the text that relies upon assumptions of temporal progression; and (3) enabling images and "objects" to "speak" through means other than traditional language/description. Bleiker and Kay's examination of HIV/AIDS through photography, Weber's examination of the war on terror through her videos on "I am an American," as well as Sylvester's analysis of the relationship between IR and Art Museums, provide some examples of how this can be achieved. The risk of some of these analyses is, however, that of creating an oversimplified system of "add image and stir." To avoid that, a more consistent consideration of the methodological implications of such interventions is essential.

While some of the methods listed above are only roughly explored in this essay, Benjamin's work does provide enough ground to sustain a more in-depth exploration on exactly how this could be done, with more specific guidelines that could easily be extracted from Benjamin's own methods of writing and collecting. Benjamin's critique of classical text however has much more important implications for the ontological foundation of IR. While the dualist-monist division between different IR ontologies has been carefully examined by people such as Patrick Jackson (Jackson 2008), Benjamin's version of monism provides a more essential critique of the reliance of knowledge on language and the possibility of attaining knowledge outside of traditional linguistic practices (as reflected in text for example.) By arguing that thoughts and ideas, as expressed through language are nothing but organizational devices, Benjamin places the possibility of attaining "truth" clearly outside of language and text and instead, within the revelatory potential of the material world/objects. This radically shifts not only the role of social sciences in general, but also the role of the intellectual/researcher, from that of a writer that seeks "truth" to that of a collector/critic that unintentionally stumbles upon "truth." 
The three volumes examined in the essay seek to portray a different facet of Benjamin's "new philosophy," from his identification of the material object as the main object of study, to his treatment of history, temporality and change to his textual/collage practices and his fascination with images and representation as a particular alternative to classical text. Each of them is representative of a particular way of implementing Benjamin's larger methodology, suggesting that Benjamin's fragmented work is not only a sign of an "unfinished" project but rather of an intentionally fragmented project. Using these volumes as a way to frame the larger argument-as opposed to offering a more classical critical review of these volumes-the essay hopes to have instilled more interest in Benjamin's work and more importantly in future explorations of his particular methodology and its possible implications for IR.

\section{References}

Arens, Katherine. (2007) Stadtwollen: Benjamin's Arcades Project and the Problem of Method. PMLA: Publication of the Modern Languages Association of America 122(1): 43-60.

Barker, Adele Marie, ED. (1999) Consuming Russia: Popular Culture, Sex, and Society Since Gorbachev. Durham, NC, and London: Duke University Press.

Benjamin, Walter. (1982) The Arcades Project. Trans. by H. Eiland and K. McLaughlin. Cambridge: Belknap Press of Harvard University Press.

Benjamin, Walter. ([1963] 1998) The Origin of German Tragic Drama. London, New York: Verso.

Bleiker, Roland. (2001) The Aesthetic Turn in International Political Theory. Millennium: Journal of International Studies 30(3): 509-533.

Bleiker, Roland, ANd Amy Kay. (2007) Representing HIV/AIDS in Africa: Pluralist Photography and Local Empowerment. International Studies Quarterly 51(1): 139-163.

Blum, Martin. (2000) Remaking the East German Past: Ostalgie, Identity, and Material Culture. Journal of Popular Culture 34(3): 229-253.

Boym, Svetlana. (2001) The Future of Nostalgia. New York: Basic Books.

Buck-Morss, Susan. (2000) Dreamworld and Catastrophe: The Passing of Mass Utopia in East and West. Cambridge and London: MIT Press.

Caygill, Howard. (1998) Walter Benjamin: The Colour of Experience. London and New York: Routledge.

Closs-Stephens, Angharad. (2009) Walter Benjamin and International Relations. In Critical Theorists and International Relations, edited by J. Edkins. London and New York: Routledge.

Davies, Matthew, and Michael Niemann. (2008) International Relations E Everyday Life. New York and London: Routledge.

GeARING, Robin E. (2004) Bracketing in Research: A Typology. Qualitative Health Research 14(10): 1429-1452.

Jackson, Patrick T. (2008) Foregrounding Ontology: Dualism, Monism and IR Theory. Review of International Studies 34(1): 129-153.

LeVasseur, Jeanne J. (2003) The Problem of Bracketing in Phenomenology. Qualitative Health Research 13(3): 408-420.

Marx, Ursula, Gudrun Schwartz, Michael Schwartz, and Erdmut Wizisla, Eds. (2007) Walter Benjamin's Archive. London and New York: Verso.

Moore, Cerwyn. (2006) Reading the Hermeneutics of Violence: The Literary Turn and Chechnya. Global Society 20(2): 179-198.

Pusca, Anca. (2008) The Aesthetics of Change: Exploring Post-Communist Spaces. Global Society 22(3): 369-386.

Pusca, AncA. (2009a) Restaging the Romanian Revolution: 1989 in Today's Visual Imaginary. In Escaping Transition: Narratives of Post-Communism in Bulgaria and Romania, edited by M. Ivanova and L. Kaganovsky. New York and London: Routledge (forthcoming).

Pusca, Anca. (2009b) Industrial and Human Ruins in Post-Communist Europe. Space and Culture 12(4) (forthcoming).

Roman, Denise. (2003) Fragmented Identities: Popular Culture, Sex, and Everyday Life in Postcommunist Romania. Lanham, Boulder, New York, Toronto and Plymouth: Lexington Books.

Schwartz, R. Vanessa. (2000) Walter Benjamin for Historians. The American Historical Review 106(5): $1721-1743$. 
Sylvester, Christine. (2009) Art/Museums: International Relations Where We Least Expect It. Boulder and London: Paradigm.

Weber, Cynthia. (2007) 'I am an American': Portraits of Post-9/11 US Citizens. Available at: http://www.opendemocracy.net/article/democracy_power/america_power_world/citizen_identity. (Accessed February 6, 2009).

Weigel, Sigrid. (1996) Body and Image Space: Re-Reading Walter Benjamin. London: Routledge. 